\title{
The Development of a Psychodiagnostic Instrument Based on Ego state, Impasse and Drama Triangle Concepts (ZESUI)
}

\author{
(C) 2012 Kristina Brajovic Car, CTA Psychotherapy, Marina Hadzi Pesic, CTA \\ Psychotherapy and Jasmina Nedeljkovic.
}

\begin{abstract}
The process of developing the final version of the Impasses, Ego state and Drama Triangle Role Inventory (in short - ZESUI) presented in this article involved repeated iterations over four years. The scale is based on the Transactional analysis theory of personality, interpersonal styles and pathology. The statistical method used in the process of the instrument development, with specific attempts to increase the factor saturation and items internal consistency is exploratory factor analysis, more specifically methods of principal component analysis. The questions within the inventory include the relevant aspects of the diagnosis (assessment) of the Ego state, Impasses and Roles profiles. It consists of 62 items which measure three types of Impasses: Type I, II and III, nine Functional Ego States and three Drama Triangle Roles: Rescuer, Persecutor and Victim.
\end{abstract}

\section{Introduction}

The most significant objection to Transactional Analysis (TA), as well as to some other therapeutic schools of thought, is the lack of serious scientific and evaluation studies that could serve as guidelines for overcoming former weaknesses of clinical observations. The main difference between TA and other kinds of psychotherapy is that TA explains a person not only structurally, but also functionally.

Transactional Analysis, in a diagnostic and therapeutic sense, in contrast to many clinical theories that deal with the internal world of an individual, puts emphasis on the functional analysis of behaviour (appropriate words, gestures, postures, tones, facial expression) defined in terms of the categories of the "here and now". Research so far has shown that highly accentuated ego states of the Negative Adapted Child and Negative Nurturing Parent correlate with pathological personality tendencies (Thorne \& Faro, 1980; Kron, 1988). With the aid of a constructed egogram, it is possible to further develop a therapeutic strategy, formulate a preliminary change contract with a client and establish clear goals for the treatment. The egogram and the scale of interpersonal exchange can, as research suggests, also be employed to follow the effects of psychotherapeutic work (Petrović, 1981).

The existing TA measure instrument from which we started in this research endeavour towards further redefining and developing indicators and items was ESQ - Revised (Loffredo, 2004), a test for measuring functional personality aspects, the behavioural manifestations of ego states. The ESQ - R instrument, as a measure of the five functional ego states, is characterized by its high construct validity. The application of this instrument in correlational research conducted on the population of Serbia has yielded a reliability coefficient, Cronbach's Alpha, calculated via the method of split-half correlation, which equals 0.73 and represents a satisfactory psychometric characteristic of the questionnaire, considering the heterogeneous nature of the scale itself (Brajovic Car \& Hadzi Pesic, 2011).

In light of these facts, we could conclude that an empirical verification of the TA personality model is possible. On the other hand, based on many years of clinical experience and research practice, we as a research team have assumed that the existence of a comprehensive, standard TA clinical test could improve the initial phases of the therapeutic process. A TA clinical test would enable, in a short period of time, the precise definition of treatment goals, the formulation of the contract for change with the client as well as a provisional therapeutic strategy.

The goal of this research project was to create a possibility for uniform and reliable practice of TA clinical evaluation by developing an instrument through which the communication and exchange between colleagues would be considerably facilitated in the future. In other 
words, the standardization of a diagnostic procedure improves the quality of clinical evaluation and provides an adequate choice of therapeutic direction. Setting a TA diagnosis by means of questionnaires is independent from practitioners' skills and their personal characteristics. Practising a uniform diagnostic procedure eliminates the possibility of a negative transfer and countertransferential influence in the initial phases of the therapeutic process, especially when the evaluation of a client's present state requires a differential diagnostics competence.

The personality profile, formed on the basis of such a tool, besides psychodiagnostic purposes can also be used in the evaluation and observation of the effects of TA psychotherapeutic treatment or participation in TA psychoeducational groups. For the purpose of a wider applicability of the instrument in the construction of the questionnaire we relied on the functional fluency model (Temple, 2004) which represents a normocentric combination of the structural and functional personality models. According to this model, all functional options are in fact behavioural manifestations of the integrated Adult ego state. Within the framework of these theoretical assumptions, the subscale nine Functional Ego States was developed within the Impasses, Ego state and Drama Triangle Role Inventory (ZESUI for short).

The designed questionnaire consists of questions which integrate three of four aspects in ego states diagnosis (Berne, 1961):

- Current behavioural assessment of the client, as the behavioural clues to the Ego state diagnosis will be incorporated in the questionnaire indicators and items.

- Social diagnosis in terms of most frequently detected ego states in the interpersonal context, and type and quality of provoked responses in others.

- The involvement of intrapersonal, pathological dimensions (Impasses) in this battery of tests enables the practitioner to gain an insight into the internal personality conflict of the client (historical diagnosis) and to briefly establish an initial hypothesis.

The test comprises three types of Impasses - type I, II and III (Goulding \& Goulding, 1979), nine Functional Ego States (Temple, 2004), and three Drama Triangle Roles Rescuer, Persecutor and Victim (Karpman, 1968). Regardless of the testing, during the process of psychotherapy work, the initial hypothesis will be verified and re-evaluated through a thorough phenomenological diagnosis.

Thus, the application of this assessment tool does not exclude but rather supplements the clinical interview oriented to historical and phenomenological diagnostics, as well as an in-depth script analysis with the client. However, in non-clinical settings, such as work and educational environments, communal counselling or crisis intervention centres, behavioural and social diagnostics could represent a sufficient indicator for a quick and reliable analysis and assessment of the client's state preceding the psychotherapeutic relation.

\section{Study Objectives And Hypotheses}

The general theoretical goal of this research project was the empirical analysis of the theoretical constructs such as the structural and functional pathology of ego states (Contaminations, Exclusions, Drama triangle roles and Impasses) on the large scale, parametric research. The specific goal was to construct a robust and valid instrument for measuring a person's pathological tendencies based on key TA concepts.

The primary research goal is thus the construction, psychometric validation and standardization of a diagnostic tool created in line with the TA theory of personality. This multidimensional clinical test of personality would be able to register both potential personality weaknesses and strengths.

The secondary goal of our research is an empirical testing of three key TA concepts, Ego State, Impasse and Drama Roles.

\section{Funding Sources}

The construction of this instrument started in 2007 as a SATA research project under the name of The Development of a TA Diagnostic Tool for the Enhancement of Clinical Application of Transactional Analysis. The initial funding was provided by the EATA Research Committee. Besides that, additional support was raised from Serbian Universities (Belgrade, Nis and Novi Sad), in terms of technical assistance in the administration of questionnaires. The development began in 2007/2008 and concluded in 2011. The results were publicly presented twice, at the EATA and SATA summer school held in 2009 in Belgrade (the first version of the instrument) and at the EATA conference held in Prague, 2010.

\section{Methodology}

Regarding the general methodology, this research is a non-experimental large scale exploratory research on the general public. Its aim is the construction and standardization of a diagnostic battery of TA clinical personality tests.

The sample consists of student population from three cities in Serbia. All interviewees in the sample represent the urban population (citizens of Belgrade, Nis, and Novi Sad). More precisely, the results of the research could be generalized exclusively to the population of urban areas. More comprehensive (normative) results could be obtained by including interviewees from rural areas in a selected sample. Independent variables that are assumed to have a potential intervening influence on the variation of the research results are: gender and age of interviewees. In order to standardize this instrument for a specific culture and to provide norms and a practitioner manual for administration and calculation, 
the sample must contain at least 1000 interviewees or more.

The variables in the conducted research objectively expressed the quality and degree of the structural and functional pathology of Ego states, Drama Triangle Roles, and Impasses. These variables, postulated as psychologically dispositional, are examined indirectly by the test battery in order to register and quantitatively represent the measured variables.

The final standardized diagnostic tool consists of three different scales within the multi-dimensional test battery.

The scale that measures the functional manifestation of Ego states consists of 38 questions formulated as a fivedegree Likert type scale. This questionnaire contains nine subscales. Each of them measures one Functional Ego state: Negative Nurturing Parent (-NP), Positive Nurturing Parent (+NP), Negative Controlling Parent ($\mathrm{CP})$, Positive Controlling Parent $(+\mathrm{CP})$, Integrated Adult (A), Negative Free Child (-FC), Positive Free Child (+FC), Negative Adapted Child (-AD), Positive Adapted Child $(+A C)$. On the basis of the numerically expressed scores on the scales for $-\mathrm{NP},-\mathrm{CP},-\mathrm{AC},-\mathrm{FC}$, it is possible to set a preliminary clinical hypothesis about structural sources of contaminations, as well as about potential exclusions of certain Ego states (energy distribution among Ego states).

The second part of the battery includes a scale that measures tendencies for acting from particular positions on the Drama Triangle. It consists of 12 questions, also in the form of a five-degree scale. This questionnaire contains three subscales, and each of them measures one of three Drama Roles (Rescuer, Persecutor and Victim), recognized by Karpman's (1968) model of the Drama Triangle as the central theoretical concept in recognizing and understanding dysfunctional interpersonal relations.

The third scale within the battery has as its goal the registration and measuring of the impasses, as indicators of the structural pathology of ego states. Three clinically recognized and theoretically based types of intrapersonal Impasses, classified as type I, II and III, are measured by the five-degree scale within the battery of tests. Each of these three subscales will measure one type of the existent personality Impasses.

Throughout the process of instrument validation, we have applied the Exploratory factor analysis (from hereafter EFA) using the method of principal components first with Varimax rotation applied to the results of Ego states subscales, and later separately for every segment of the questionnaire. The aim of the analysis of the main components is to transform the $n$ measured and interrelated variables into non-correlated main components. The practical aim of this analysis is to retain, from all the main components received on the basis of $\mathrm{n}$ original, measured variables, only a limited number of components which will contain as large a portion as possible of the total variance (or amount of information) of all the original, i.e., measured variables. As opposed to factor analysis proper, with which we attempt to explain connections (i.e., correlations, between manifest, measured variables), we strive with component methods to explain the variances in the measures of the studied phenomenon by discovering its causes.

\section{Steps in the Instrument Development}

The instrument is designed as a list of statements that the subjects provide an answer for, based on the extent to which they agree with an item. The applied scale is a Likert scale. The quantifiers offered are $1-$ I completely disagree, $2-1$ moderately disagree, $3-1$ am undecided, 4-I moderately agree and $5-$ I completely agree. The items are constructed based on the indicators of a certain variable. They are written in the form of statements.

In the first two steps, two versions of the questionnaire have been tested on samples of 150 subjects each.

The first version of the questionnaire had 165 items with a five-degree answer scale (from 1 = completely disagree to $5=$ completely agree). It was tested in March 2007.

Reliability was Alpha $=0.84$. A VARIMAX rotation factor analysis revealed nine primary factors corresponding to the nine Functional Ego states.

The cumulative percent of the explained variances by nine factors was 64.88 .

Thus, the factor analysis of this Questionnaire revealed that it does measure nine Functional Ego states (factors), albeit with a varying accuracy.

The next revised version had 112 questions. It was checked in November 2007.

Reliability was Alpha $=0.91$ A VARIMAX rotation factor analysis revealed nine factors explained $67.25 \%$ of the variance, with accuracy still varying. The improvement in the scale is expressed in the increase of reliability quotient, as the statistical error in measure is smaller, i.e., the percentage of variability among participants has been increased, which can be explained precisely via the scale.

The final version of the part of the questionnaire to do with diagnosing Ego States has 38 questions.

In 2008 and 2009, the items for Impasses and Drama Roles were developed. In 2010, the Impasse and Drama Role factor structures of the questionnaire were checked, 33 questions were kept out of the total of 135 questions.

In the first half of 2011, research was conducted in which the final version of the ZESUI questionnaire was used (ZESUI - Impasses Ego States Roles Inventory IESRI), consisting of 78 Likert question items.

The content of the questionnaire includes: 18 Impasse items, 45 Ego State items, and 15 Role items.

The participants in the sample were students from several regions in Serbia. The data was collected from 418 participants of various ages and both genders. 111 questionnaires were discarded from the analysis as they 
had not been filled out correctly. The analysis was carried out on 307 participants. The mean age of the participants was $21.63(\mathrm{sd}=3.249) .18 .6 \%$ participants were male and $81.4 \%$ were female.

\section{Presentation and Analysis Of Results}

The questionnaire Impasses, Ego States and Drama Roles Inventory (in Serbian - ZESUI) consists of three separate parts and contains 78 items. The first subscale contains 18 items and its aim is to investigate which type of Impasse is dominant. The second part contains 45 items and aims to investigate which Ego State is dominant. The third part contains 15 items and explores which Role is dominant. The ZESUI Reliability, measured as Cronbach's Alpha, was 0.84. This level of the reliability indicator suggests a satisfactory psychometric adequacy and validity of the constructed test.

We have excluded from further analysis the items which had significant and high saturation on two factors (i.e. were multi-saturated), so the final analysis was carried out on the total of 62 items. The Impasse subscale had 12 items, the Ego States subscale had 38 items and the Roles subscale had 12 items. When ascertaining the ZESUI Reliability of the 62 items instrument, the measured Cronbach's Alpha was 0.82. After a certain number of items were discarded, the desired reliability of internal consistency was achieved. The Alpha coefficient is in the medium range, which speaks for the reliability of the data gathered in this test.

\section{ZESUI: Description of three subscales in the questionnaire}

Scale length: 62 items. These items are split into 3 scales named:

- Impasse (12 items). These items are split into 3 subscales named:

- Impasse I degree (4 items),

- Impasse II degree (4 items),

- Impasse III degree (4 items).

- $\quad$ Ego states ( 38 items). These items are split into 9 subscales named:

- $\quad(-)$ AC (5 items),

- (+) CP (4 items),

- (+) NP (4 items),

- $\quad(-)$ NP (5 items),

- (+) FC (4 items),

- (+) AC (4 items),

- $(-)$ CP (4 items),

- A (4 items),

- (-) FC (4 items).

- Drama Triangle Role (12 items). These items are split into 3 subscales named:

- $\operatorname{Victim}(4$ items),

- Rescuer (4 items),

- Persecutor (4 items).
Descriptive characteristic of dimension of ZESUI on the Serbian sample indicates the interval of average population result on each subscale, and the dispersion of the individual results around the average. Although it was not the primary aim of the research, based on the above results, it can be concluded that among the sample of Serbian students the dominant ego state is that of the Positive Adapted Child ( $A C+)$, the intrapersonal impasse of the third type, as well as the interpersonal role of the Rescuer. We will further comment on the obtained results in the discussion.

\section{EFA Results for the Impasse part}

The reliability of the Impasse part (12 items) measured as Cronbach's Alpha was 0.72 . This measure indicates a satisfactory validity of the subscale.

The three factor saturation was further analyzed, by the measurement of the sampling adequacy $(\mathrm{KMO}=0.751)$. The three factors obtained explain $52.46 \%$ of the total variance. The obtained factors allow the following reading: factor 1 : ( $24.84 \%$ of variance explained) can be named IMPASSE 2; factor 2: (15.45 \% of variance explained) resembles the IMPASSE 3; factor 3: (12.17\% of variance explained) is similar in structure to the IMPASSE 1 . Single item correlation with the factor it measures is presented in the table below. The extraction method used for the analysis was principal component analysis. Rotation method was Varimax with Kaiser Normalization. A rotation converged in 5 iterations.

\section{EFA Results for the Ego States part} The reliability of the Ego States part ( 38 items) was Cronbach's Alpha $=0.76$.

The nine-factor saturation was further analyzed, by measuring the sampling adequacy $(\mathrm{KMO}=0.787)$. The nine factors obtained explain $53.80 \%$ of the total variance. The obtained factors allow the following reading: factor 1 : (7.78\% of variance explained) can be named - AC; factor 2: (6.90\% of variance explained) resembles the $+\mathrm{CP}$; factor 3 : ( $6.49 \%$ of variance explained) is similar in structure to the +NP; factor 4 : (6.20\% of variance explained) can be named -NP; factor 5: (5.94 \% of variance explained) can be named $+\mathrm{FC}$; factor 6: (5.81\% of variance explained) can be named +AC; factor 7: (5.16\% of variance explained) can be named -CP; factor 8: (4.89\% of variance explained) can be named $A$; factor 9 : (4.62\% of variance explained) can be named $-\mathrm{FC}$;

The extraction method used for analysis was principal component analysis. Rotation method was Varimax with Kaiser Normalization. A Rotation converged in 10 iterations.

Note: * item score reversed

EFA Results for the Role in Drama Triangle

part

The reliability of the Roles part (12 items) was

Cronbach's Alpha $=0.67$ 
The three -factor saturation was further analyzed, by the measurement of the sampling adequacy ( $\mathrm{KMO}=0.687$ ). The three factors obtained explain $50.49 \%$ of the total variance. The obtained factors allow the following reading: factor 1 : ( $18.56 \%$ of variance explained) can be named Victim; factor 2: (17.24 \% of variance explained) resembles the Rescuer; factor 3: ( $14.69 \%$ of variance explained) is similar in structure to the Persecutor.

The extraction method used for the analysis was principal component analysis. Rotation method was Varimax with Kaiser Normalization. A rotation converged in 4 iterations.

\section{Table 1: Descriptive Statistics}

\begin{tabular}{|l|l|l|l|l|}
\hline & Minimum & Maximum & Mean & Std. Deviation \\
\hline Impasse I & 1.00 & 5.00 & 2.0136 & .89456 \\
\hline Impasse II & 1.00 & 4.50 & 1.8633 & .84288 \\
\hline Impasse III & 1.00 & 4.50 & 2.6860 & .69811 \\
\hline Victim & 1.00 & 4.50 & 2.0943 & .76333 \\
\hline Rescuer & 1.00 & 5.00 & 3.0534 & .89336 \\
\hline Persecutor & 1.00 & 5.00 & 2.7883 & .81701 \\
\hline AC- & 1.00 & 4.80 & 2.4493 & .82805 \\
\hline CP+ & 1.00 & 5.00 & 2.9761 & .90227 \\
\hline NP+ & 1.50 & 5.00 & 3.7572 & .75984 \\
\hline NP- & 1.00 & 4.60 & 3.0852 & .70112 \\
\hline FC+ & 1.00 & 5.00 & 3.6258 & .78616 \\
\hline AC+ & 1.50 & 5.00 & 4.0773 & .85149 \\
\hline CP- & 1.25 & 5.00 & 2.9621 & .64098 \\
\hline A & 1.33 & 5.00 & 3.7689 & .79010 \\
\hline FC- & 1.00 & 4.33 & 2.3295 & .79488 \\
\hline
\end{tabular}

Table 2: Rotated Component Matrix - Consummation of alcohol and narcotics

\begin{tabular}{|c|c|c|c|}
\hline & \multicolumn{3}{|c|}{ Component } \\
\hline & 1 & 2 & 3 \\
\hline I do not like people who gesture a lot when they speak. & & & .573 \\
\hline I think that it is in poor taste to be showing one's weakness in front of other people. & & & 615 \\
\hline I have the impression I often frown when I speak. & & & .530 \\
\hline I am always in a hurry and I never manage to get things done. & & & .612 \\
\hline I am angry at my parents because they have let me down. & .635 & & \\
\hline $\begin{array}{l}\text { Because my parent was critical of me, I found it difficult to make decisions } \\
\text { independently. }\end{array}$ & .707 & & \\
\hline $\begin{array}{l}\text { As a child, I was often ridiculed and reprimanded over what I did and how I } \\
\text { thought. }\end{array}$ & .766 & & \\
\hline I was never getting the support I wanted for being original, brave or for taking risks. & .787 & & \\
\hline Alcohol consumption gets me into social and health problems. & & .882 & \\
\hline Excessive consumption of medications or other narcotics creates problems for me. & & .890 & \\
\hline I have almost no close friends. & & .287 & \\
\hline I feel uncomfortable and tense around people. & & .237 & \\
\hline
\end{tabular}


Table 3: Rotated Component Matrix - Prevalence of Adult, Positive AC and Positive CP

\begin{tabular}{|c|c|c|c|c|c|c|c|c|c|}
\hline & Com & nent & & & & & & & \\
\hline & 1 & 2 & 3 & 4 & 5 & 6 & 7 & 8 & 9 \\
\hline I very quickly give up things I do not do well. & 옹 & & & & & & & & \\
\hline I often feel helpless. & 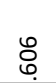 & & & & & & & & \\
\hline I am angry at myself for being dependent on others. & ఫ্ & & & & & & & & \\
\hline * I am satisfied with how I manage my own time. & 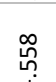 & & & & & & & & \\
\hline $\begin{array}{l}\text { No matter how much I try, I fail to meet the needs of } \\
\text { people who are closest to me. }\end{array}$ & மீ & & & & & & & & \\
\hline $\begin{array}{l}\text { I am happy to take the role of a leader in solving } \\
\text { problems. }\end{array}$ & & $\stackrel{\infty}{\sim}$ & & & & & & & \\
\hline In the circle of my friends, I rule the roost. & & 옦 & & & & & & & \\
\hline I like to be in the centre of attention. & & શิ & & & & & & & \\
\hline I have always had good negotiation ("diplomatic") skills. & & 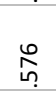 & & & & & & & \\
\hline $\begin{array}{l}\text { In the interactions with other people, I always try to be } \\
\text { aware of my feelings as well as feelings of others. }\end{array}$ & & & $\stackrel{\varphi}{\stackrel{7}{r}}$ & & & & & & \\
\hline $\begin{array}{l}\text { I find it easy to successfully communicate with a wide } \\
\text { variety of people. }\end{array}$ & & & ชิ & & & & & & \\
\hline $\begin{array}{l}\text { I think that to maintain a friendship, you must } \\
\text { acknowledge needs and feelings of others and yourself. }\end{array}$ & & & ర্ঠ & & & & & & \\
\hline $\begin{array}{l}\text { People in my surroundings often come to me for help or } \\
\text { advice }\end{array}$ & & & $\stackrel{n}{n}$ & & & & & & \\
\hline I always help others, even when it is not necessary. & & & & $\stackrel{\text { صै }}{\vec{\varphi}}$ & & & & & \\
\hline I feel obligated to come to the aid of others. & & & & $\stackrel{\infty}{0}$ & & & & & \\
\hline $\begin{array}{l}\text { It is important for me to actively motivate and inspire } \\
\text { people close to me by my own example. }\end{array}$ & & & & $\begin{array}{l}\infty \\
\infty \\
\stackrel{\infty}{n}\end{array}$ & & & & & \\
\hline My friends know how I feel, just by hearing my voice. & & & & $\stackrel{n}{n}$ & & & & & \\
\hline $\begin{array}{l}\text { I think other people's mistakes and oversights should } \\
\text { always be pointed out to them in a nice way. }\end{array}$ & & & & กิ & & & & & \\
\hline $\begin{array}{l}\text { People around me like me because of my sense of } \\
\text { humour. }\end{array}$ & & & & & $\ddot{\mathscr{ర}}$ & & & & \\
\hline $\begin{array}{l}\text { Based on the behaviour of others towards me, you could } \\
\text { say I am a friendly and confident person. }\end{array}$ & & & & & ஜึ & & & & \\
\hline People in my surroundings see me as optimistic. & & & & & กี & & & & \\
\hline $\begin{array}{l}\text { I am not afraid to show my true self in the company of } \\
\text { anyone. }\end{array}$ & & & & & ஸี & & & & \\
\hline $\begin{array}{l}\text { I do not allow someone to impose their views on me } \\
\text { when my judgment is that he/she is wrong. }\end{array}$ & & & & & & $\underset{\sqcup}{\text { ఫ్ }}$ & & & \\
\hline $\begin{array}{l}\text { I pursue my own interest, but I am doing it without } \\
\text { detriment to others' rights. }\end{array}$ & & & & & & ํํ & & & \\
\hline I try to help my family members at any cost. & & & & & & જ્ & & & \\
\hline
\end{tabular}




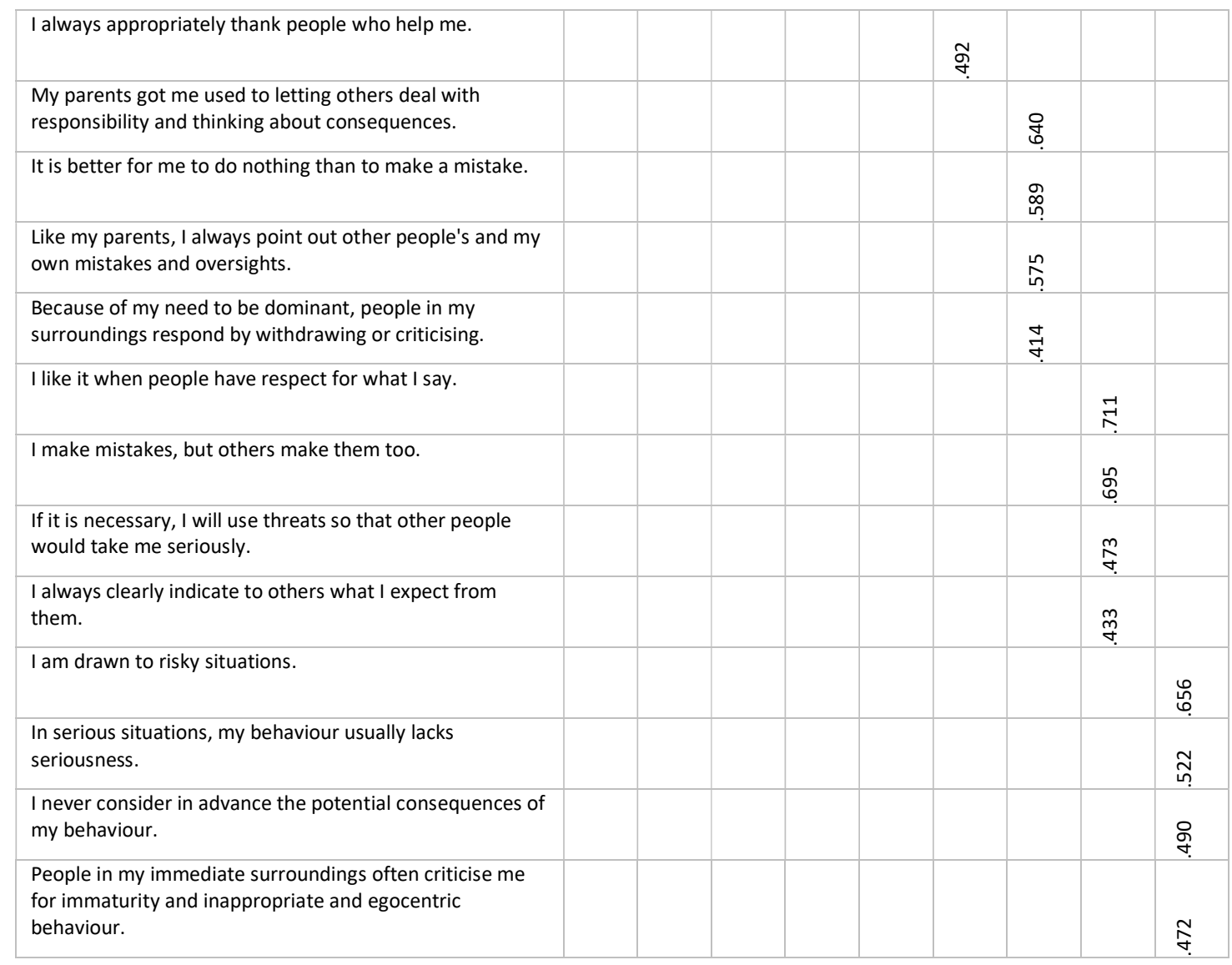

Table 4: Rotated Component Matrix - Drama Triangle Roles

\begin{tabular}{|c|c|c|c|}
\hline & \multicolumn{3}{|c|}{ Component } \\
\hline & 1 & 2 & 3 \\
\hline I am unable to help myself. & .774 & & \\
\hline I often think I am a hopeless case. & .806 & & \\
\hline At work, I let others make the decisions. & 615 & & \\
\hline I give others too much leeway to control my life (and take care of me) & .714 & & \\
\hline It seems to me that I always work more than my fair share. & & 688 & \\
\hline $\begin{array}{l}\text { Sometimes it seems to me that I look after the people (who I love) who ought to take } \\
\text { care of themselves and that I solve problems for them. }\end{array}$ & & .766 & \\
\hline Friends often tell me I am too ready to be of help to others. & & .789 & \\
\hline I like to feel needed (- to always help). & & .563 & \\
\hline When I am angry, I cannot control myself. & & & .662 \\
\hline I have the right to be angry and furious over other people's mistakes. & & & .661 \\
\hline I am prone to frequent criticizing (of others). & & & .559 \\
\hline It often happens that I interrupt others when they are speaking. & & & 695 \\
\hline
\end{tabular}




\section{Discussion and Conclusions}

The questionnaire developed within the presented research project has certain specificities which should be further discussed. As far as the psychometric evaluation of the test is concerned, an examination of the factor structure of the test on a sample has confirmed that the test possesses a satisfactory level of validity. All the values received for the representability of sample items according to factors, expressed individually for each subscale within the ZESUI instrument, are above the minimum level of acceptability (0.30). The items which are most saturated by the factors they measure are those pertaining to examining the tendencies towards the consummation of alcohol and narcotics within the factor Impasses (see Table 2). Then, the items which measure the prevalence of the ego states Adult, Positive Adapted Child and Positive Critical Parent, are most saturated by the factors separated within the subscale which examines the functional profile of the ego states (see Table 3). Within the Drama roles subscale, the items which are saturated by presupposed, but also empirically confirmed factors, are those we use to examine the tendency to assume the positions of the Victim and the Rescuer (see Table 4). Nevertheless, due to possible cultural differences, before any psychodiagnostic use in other cultures, the items should certainly be adapted via a pilot application of the questionnaire.

Also, when the psychodiagnostic application of the test is concerned, with the goal of determining the norms for evaluating the participants, it is necessary to set a questionnaire on a normative sample, by which a wider demographic range is understood, containing represented categories according to age, education, and social status, representative of the concrete population in question. At the level of Serbia, the project team has just commenced the standardization of the questionnaire. The national sample based on which the norms will be created consists of 600 participants and satisfies the mentioned criteria of representability. The next step which will advance the applicability of the test is creating a manual for practitioners on the basis of which a quick interpretation of the results will be possible in clinical conditions, but also in other areas of applied psychology which involve psychological evaluation. As has already been stressed in the introduction, setting a TA diagnosis by means of questionnaires is independent from practitioners' skills and their personal characteristics.

At the level of correlational studies, in its present version the test is applicable, for example, in crosscultural research into the connection between parenting styles and family dynamics on the one hand and the dominant ego state, roles and impasses on the other.

During the course of the construction and psychometric validation of the test, several intriguing insights were gathered, which were not the goal of the research in their own right. One of them is a cultural profile that we reached in the process of constructing the ZESUI questionnaire. The dominant ego state is that of the Positive Adapted Child, the drama role is that of the Rescuer, as well as an impasse of the third type. Based on the cited discoveries, we could discuss the psychosocial characteristics of the cultural script which requires a reactive personality type, being decentred, insufficiently introspective, and directed towards the other, as well as an identity crisis (which is typical of societies in a prolonged state of transition).

The research team consists of psychologists in different specialization domains: Kristina Brajovic Car, CTA (P), member of SATA, Marina Hadzi Pesic, CTA (P), member of SATA, and Jasmina Nedeljkovic, the statistics and psychometric consultant on the project.

\section{References}

Berne, E. (1961). Transactional analysis in psychotherapy. New York: Ballantine Books.

Brajovic Car, K. \& Hadzi Pesic, M. (2010). Evaluation of psychotherapeutic effects with TA multidimensional personality test. Paper presented at "TA Metamorphosis" EATA Conference, Prague, Czech Republic.

Brajovic Car, K. \& Hadzi Pesic, M. (2011). Differences in marital satisfaction depending on Egogram profile and Interpersonal styles of partners. Ljetopis socijalnog rada, 18(1), 63-81.

Clarkson P. (1992). Transactional analysis psychotherapy. London: Routledge.

Dusay, J. (1977). Egograms. New York: Harper and Row.

Goulding, M. \& Goulding, R. (1979). Changing lives through redecision therapy. New York: Brunner/Mayel.

Karpman, S. (1968). Fairly tales and script drama analysis, $T A$ Bulletin. 7 (26). 39-43.

Kron, L.(1988). Modeli u Transakcionoj analizi. Časopis Psihologija. Savez društava psihologa Srbije, 21 (1-2).

Lapworth P., Sills C., Fish S. (1993). Transactional Analysis Counselling, Oxfordshire: Winslow Press Limited.

Loffredo, D. A., Harrington, R., Munoz, M. K., \& Knowles, L. R. (2004). The ego state questionnaire-Revised. Transactional Analysis Journal. 34 (1) 90-95.

Petrović, V. (1981). Egogrami kao način praćenja promena u psihoterapiji. Diplomski rad. Beograd: Filozofski fakultet Univerzita u Beogradu.

Stewart I., Joines V. (2000). TA Today. Nottingham: Lifespace Publishing.

Temple, S. (2004). Update on the Functional Fluency Model in Education. Transactional Analysis Journal, 34 (3). 197-204.

Thorne, S. \& Faro, S. (1980). The ego state scale: A measure of psychopathology. Transactional Analysis Journal, 10 (1). 49-52.

Woollams S., Brown M. (1979). The Total Handbook of Transactional Analysis. Englewood Cliffs, NJ: Prentice-Hall. 


\section{Appendix: ZESUI INVENTORY}

The translation of items is from Serbian to English. It is advisable to accommodate translation to a culture of a spoken language, before application of the questionnaire.

PLEASE RESPOND HONESTLY TO THE STATEMENTS BELOW BY CIRCLING ONE NUMBER FROM 1 TO 5, DEPENDING ON THE EXTENT TO WHICH EACH STATEMENT PERTAINS TO YOU.

$1=$ the statement does not apply to me at all; $2=$ the statement is more untrue than true; $3=$ the statement is half true and half untrue; $4=$ the statement is more true than untrue; $5=$ the statement fully applies to me

\begin{tabular}{|c|c|c|c|c|c|}
\hline I am angry at my parents because they have let me down. & 1 & 2 & 3 & 4 & 5 \\
\hline Alcohol consumption gets me into social and health problems. & 1 & 2 & 3 & 4 & 5 \\
\hline I do not like people who gesture a lot, when they speak. & 1 & 2 & 3 & 4 & 5 \\
\hline $\begin{array}{l}\text { Because my parent was critical of me, I found it difficult to make decisions } \\
\text { independently. }\end{array}$ & 1 & 2 & 3 & 4 & 5 \\
\hline Excessive consumption of medications or other narcotics creates problems for me. & 1 & 2 & 3 & 4 & 5 \\
\hline I think that it is inadequate to be showing one's weakness in front of other people. & 1 & 2 & 3 & 4 & 5 \\
\hline As a child, I was often ridiculed and reprimanded over what I did and how I thought. & 1 & 2 & 3 & 4 & 5 \\
\hline I have almost no close friends. & 1 & 2 & 3 & 4 & 5 \\
\hline I have the impression I often frown when I speak. & 1 & 2 & 3 & 4 & 5 \\
\hline I was never getting the support I wanted for being original, brave or for taking risks. & 1 & 2 & 3 & 4 & 5 \\
\hline I feel uncomfortable and tense around people. & 1 & 2 & 3 & 4 & 5 \\
\hline I am always in a hurry and I never manage to get things done. & 1 & 2 & 3 & 4 & 5 \\
\hline I am unable to help myself. & 1 & 2 & 3 & 4 & 5 \\
\hline It seems to me that I always work more than my fair share. & 1 & 2 & 3 & 4 & 5 \\
\hline When I am angry, I cannot control myself. & 1 & 2 & 3 & 4 & 5 \\
\hline I often think I am a hopeless case. & 1 & 2 & 3 & 4 & 5 \\
\hline $\begin{array}{l}\text { Sometimes it seems to me that I look after the people, who I love, who ought to take } \\
\text { care of themselves and that I solve problems for them. }\end{array}$ & 1 & 2 & 3 & 4 & 5 \\
\hline I have the right to be angry and furious over other people's mistakes. & 1 & 2 & 3 & 4 & 5 \\
\hline At work, I let others make the decisions. & 1 & 2 & 3 & 4 & 5 \\
\hline Friends often tell me I am too ready to be of help to others. & 1 & 2 & 3 & 4 & 5 \\
\hline I am prone to frequent criticising of others. & 1 & 2 & 3 & 4 & 5 \\
\hline I give others too much leeway to control my life and take care of me. & 1 & 2 & 3 & 4 & 5 \\
\hline I like to feel needed, to always help. & 1 & 2 & 3 & 4 & 5 \\
\hline It often happens that I interrupt others when they are speaking. & 1 & 2 & 3 & 4 & 5 \\
\hline I very quickly give up on the things I do not do well. & 1 & 2 & 3 & 4 & 5 \\
\hline I am happy to take the role of the leader in solving problems. & 1 & 2 & 3 & 4 & 5 \\
\hline I always try to empathize with other people. & 1 & 2 & 3 & 4 & 5 \\
\hline I always help others, even when it is not necessary. & 1 & 2 & 3 & 4 & 5 \\
\hline People around me like me because of my sense of humour. & 1 & 2 & 3 & 4 & 5 \\
\hline $\begin{array}{l}\text { I do not allow someone to impose their views on me when my judgment is that } \\
\text { he/she is wrong. }\end{array}$ & 1 & 2 & 3 & 4 & 5 \\
\hline I never relinquish responsibility to others. & 1 & 2 & 3 & 4 & 5 \\
\hline
\end{tabular}




\begin{tabular}{|c|c|c|c|c|c|}
\hline I expect people to respect what I have to say. & 1 & 2 & 3 & 4 & 5 \\
\hline I am drawn to risky situations. & 1 & 2 & 3 & 4 & 5 \\
\hline I often feel helpless. & 1 & 2 & 3 & 4 & 5 \\
\hline In the circle of my friends, I rule the roost. & 1 & 2 & 3 & 4 & 5 \\
\hline I find it easy to successfully communicate with a wide variety of people. & 1 & 2 & 3 & 4 & 5 \\
\hline I feel obligated to come to the aid of others. & 1 & 2 & 3 & 4 & 5 \\
\hline You could say I am a friendly and confident person. & 1 & 2 & 3 & 4 & 5 \\
\hline I seek my own well being but I try to do this without detriment to others. & 1 & 2 & 3 & 4 & 5 \\
\hline It is better for me to do nothing than to make a mistake. & 1 & 2 & 3 & 4 & 5 \\
\hline I make mistakes, just like others make mistakes. & 1 & 2 & 3 & 4 & 5 \\
\hline In serious situations, my behaviour usually lacks seriousness. & 1 & 2 & 3 & 4 & 5 \\
\hline I am angry at myself for being dependent on others. & 1 & 2 & 3 & 4 & 5 \\
\hline I like to be in the centre of attention. & 1 & 2 & 3 & 4 & 5 \\
\hline $\begin{array}{l}\text { To maintain a friendship, you must acknowledge the needs and feelings of others and } \\
\text { yourself. }\end{array}$ & 1 & 2 & 3 & 4 & 5 \\
\hline The most important thing for me is to make the people close to me happy. & 1 & 2 & 3 & 4 & 5 \\
\hline People in my surroundings see me as optimistic. & 1 & 2 & 3 & 4 & 5 \\
\hline I try to help my family members as much as I can. & 1 & 2 & 3 & 4 & 5 \\
\hline $\begin{array}{l}\text { I am a quick learner and I point out both my own and other people's mistakes and } \\
\text { oversights. }\end{array}$ & 1 & 2 & 3 & 4 & 5 \\
\hline If it is necessary, I will raise my voice so that other people would take me seriously. & 1 & 2 & 3 & 4 & 5 \\
\hline I never consider in advance the potential consequences of my behaviour. & 1 & 2 & 3 & 4 & 5 \\
\hline However much I try, I fail to meet the needs of people who are closest to me. & 1 & 2 & 3 & 4 & 5 \\
\hline I have always had good leadership skills. & 1 & 2 & 3 & 4 & 5 \\
\hline People in my surroundings often come to me for help or advice. & 1 & 2 & 3 & 4 & 5 \\
\hline $\begin{array}{l}\text { It is enough for me to just hear somebody's voice to know what they need and how } \\
\text { they are feeling. }\end{array}$ & 1 & 2 & 3 & 4 & 5 \\
\hline I am not afraid to show my true self in the company of anyone. & 1 & 2 & 3 & 4 & 5 \\
\hline I can thank people who help me appropriately. & 1 & 2 & 3 & 4 & 5 \\
\hline $\begin{array}{l}\text { People in my surroundings respond to me being dominant by withdrawing or } \\
\text { criticising. }\end{array}$ & 1 & 2 & 3 & 4 & 5 \\
\hline I always clearly indicate to others what I expect from them. & 1 & 2 & 3 & 4 & 5 \\
\hline People in my immediate surroundings often criticise me for inappropriate behaviour. & 1 & 2 & 3 & 4 & 5 \\
\hline I am satisfied with how I manage my own time. & 1 & 2 & 3 & 4 & 5 \\
\hline I think you should always disregard other people's mistakes and oversights. & 1 & 2 & 3 & 4 & 5 \\
\hline
\end{tabular}

\section{Note:}

Impasse (I, II, III, alternately, first twelve items, from 1-12 items).

Drama Roles (Victim, Rescuer, Persecutor, from 13 -24 items).

Ego States $(-A C,+C P,+N P,-N P,+F C,+A C,-C P, A,-F C$, alternately that way till 60 item; 61. item is $-A C, 62$. item is $-N P)$. 